\title{
Private Supplementary Health Insurance: Retirees' Demand
}

\author{
Carine Franc ${ }^{\mathrm{a}}$, Marc Perronnin ${ }^{\mathrm{b}}$ and Aurélie Pierre ${ }^{\mathrm{b}}$ \\ ${ }^{a}$ CERMES, Inserm U750, CNRS UMR8169, EHESS, 7 rue Guy Môquet, Villejuif 94801, France. \\ E-mail: franc@vjf.cnrs.fr \\ ${ }^{\mathrm{b}}$ IRDES, 10 rue Vauvenargues, Paris 75018, France. \\ E-mails: perronnin@irdes.fr, pierre@irdes.fr
}

In France, about 90 per cent of the population is covered by private health insurance that supplements public health insurance. More than half of policyholders obtain their coverage through their employer. Considering the financial benefits associated with group contracts compared to individual contracts, we assume that switching behaviours vary among different beneficiaries during the transition to retirement. The gap in premiums at retirement between group and individual contracts gives the opportunity to study the marginal price effect on switching behaviours. In this study, we consider the nature of the contract prior to retirement (compulsory or voluntary membership group contract and individual contract) as an indirect measure of the price effect. We show the significance of this price effect as policyholders formerly enrolled in group contracts switch much more frequently than those formerly covered by an individual contract. We also discuss other determinants of the decision to switch private supplementary health insurance.

The Geneva Papers (2008) 33, 610-626. doi:10.1057/gpp.2008.31

Keywords: private health insurance; retirement; switching behaviour

\section{Introduction}

There are different ways of studying health insurance demand, either by considering a static point of view and concentrating on the variable "insured" or "non-insured" or by considering a dynamic process and thus focusing on contract-switching behaviours on the health insurance market. Indeed, the choice of a health insurance contract by a consumer reflects the outcome of the standard trade-off linked to individual preferences and budget constraints. This choice of consumption is modified once a shock occurs: decline in health status, higher prices and so forth. The analysis of switching behaviour allows us to describe the relevant determinants of mobility on the insurance market. Numerous studies have already been carried out to identify the determinants of health insurance demand that are nowadays well attested: age, gender, income, health status, education, warranties, premiums and risk aversion. As the dynamics of demand are studied through switching behaviours, certain analyses have also emphasised market and/or institutional characteristics that may encourage or discourage these behaviours. Laske-Aldershof et al. ${ }^{1}$ provide international comparisons

\footnotetext{
${ }^{1}$ Laske-Aldershof et al. (2004).
} 
of five countries having a social health insurance system with a choice of health plan. The results point out that switching rates are higher in Germany ( 5 per cent in 2000) and Switzerland (from 2 per cent in 2000 to 4 per cent in 2002) than in Belgium ( $<1$ per cent before 2000 but reaching 2.5 per cent in 2003), the Netherlands and Israel ( $<1$ per cent in these two countries). The authors explain the higher rates by three main factors: firstly, the type of basic insurance that may offer a possible deduction level (in Switzerland); secondly, the potential monetary gains of switching that depend on the differences between premiums (higher in Germany or Switzerland than in other countries); and, finally, the level of competition. All these factors are obviously linked together and the latter depends on the size of the market, for example, the level of market concentration in Germany and Switzerland is relatively low. Competition also depends on transparency: the health insurance market is always regulated and sometimes a significant part of the warranty package is standardised across private operators (95 per cent in Germany) in order to help policyholders to compare premiums between operators. As emphasised by LaskeAldershof et al., ${ }^{2}$ the trade-off between switching costs and expected benefits at least depends on the overall organisation of the health system. The choice of insurer as well as the choice to purchase an additional health insurance contract or not may be free or restricted. For instance, in the context of a group contract with compulsory membership, policyholders did not really decide whether to purchase a supplemental health insurance contract, choose the operator or the warranties of the contract.

Whatever the analyses of individual responses to premium differences in competitive health insurance markets may be, empirical switching rates appear to be much lower than those expected in standard models of consumer demand in the case of competitive markets. Thus, studies have been carried out in order to stress and discuss the nature of barriers preventing the expression of individual preferences in the trade-off and/or in the selection actually made. Different explanations have been explored to understand this phenomenon. First, there are limitations on consumers' rationality ${ }^{3}$ and on their ability to opt for efficient contracts in highly competitive health insurance markets. Moreover, Frank and Lamiraud ${ }^{4}$ have shown that a broader range of contracts, meaning more competition, might be inefficient as the information available for the consumer becomes unreadable, thus decreasing consumers' responsiveness to differences in premiums. This has to be considered in addition to well-known transparency problems in the context of health insurance. ${ }^{5}$ Second, there are different types of switching costs (suspension period, additional premium for late enrolment, etc. ${ }^{6}$ and the monetary benefits may appear quite low compared to the total cost. Another barrier to switching from one insurer to another is the provision of an insurance package including health insurance and provident benefits. This type of contract is currently offered by

\footnotetext{
${ }^{2}$ Ibid.

${ }^{3}$ Samuelson and Zeckhauser (1988).

${ }^{4}$ Frank and Lamiraud (2008).

${ }^{5}$ Beaulieu (2002) studied the influence of information quality on consumers' health plan choices.

${ }^{6}$ In the context of HMO, we should add the potential switching cost of the health care provider.
} 
operators in the context of group contracts, making it difficult for consumers to really compare different premiums as it is much more complex to identify the price of each type of warranty.

In France, health insurance demand has recently been analysed from the static point of view. Saliba and Ventelou ${ }^{7}$ studied individual determinants for subscribing or not subscribing to a supplementary health insurance contract. As for the dynamic process, switching behaviours have also been studied through the influence of socio-economic and health characteristics. Working on a representative sample of the French population, Grignon and $\mathrm{Sitta}^{8}$ have estimated the annual switching rate in the competitive health insurance market at 12 per cent (mobility between different private health insurance operators). The authors considered a rather large number of factors to explain the switching behaviour and assumed that the choice to switch may be either the result of an individual trade-off on the one hand, or that it may be constrained on the other. Thus they showed that the switching behaviour appears to be motivated as much by individual characteristics such as age, education, state of health, etc., as by circumstances. The authors particularly emphasised the significant role of "a change in individual social economic status." 9 These results suggest that switching behaviour could be individually concentrated at a period of life such as retirement. This period is currently characterised by a potential income effect due to a decrease or increase in financial resources. Moreover, depending on the way in which individuals obtained their private health insurance contract, that is, by individual decision (individual contract) or collectively at work (group contract), retirement can be associated with an additional price effect due to the potential increase in premiums. This increase may be the result of the loss both of the employer's subsidy in the payment of the premium and of the benefit of pooling risk pricing. The impact of potential premium increases has been quite extensively studied in the U.S. Among others, Rogowski and Karoly ${ }^{10}$ showed that access to post-retirement health insurance has a rather important effect on retirement: "Among older male workers, those with retiree health benefit offers are 68 per cent more likely to retire (and those with non-employmentbased insurance are 44 per cent more likely to retire) than their counterpart who would lose employment-based health insurance upon retirement." "11 However, the debate in the U.S. concentrates much more on the role of health insurance in mobility on the labour market and more particularly in retirement decisions, whereas in France the debate focuses on the impact of retirement on mobility in the private health insurance market.

In the French context, no study has yet been carried out on the influence of differences in prices on switching behaviour at the time of retirement. This is probably due to the high complexity of supplementary health insurance added to difficulties in

\footnotetext{
${ }^{7}$ Saliba and Ventelou (2007).

${ }^{8}$ Grignon and Sitta (2003).

${ }^{9}$ In-work to retirement, in-work to unemployment, in good health to bad health and so on.

${ }^{10}$ Rogowski and Karoly (2000).

${ }^{11}$ For an overview of the literature-linking health insurance and labour market outcomes such as wages, earnings, employment hours and retirement decisions, see Currie and Madrian (1999) and Gruber (2000).
} 
collecting the actual prices paid by individuals, ${ }^{12}$ making it difficult to simultaneously control variations in premiums and warranties. Transition to retirement constitutes a specific moment for studying health insurance demand. Indeed, the transition to retirement most often occurs along with an exogenous shock in income (upwards or downwards) and with potential increases in private health insurance premiums due to the funding and charging mechanisms of group contract premiums. Thus a high switching rate during the transition to retirement for all policyholders can be expected (income effect), with a much higher rate among the enrollees of group contracts (specific price effect). The purpose of this paper is to investigate if this is indeed the case, controlling elsewhere for a number of other variables.

The rest of the paper is organised as follows. The next section describes the French context of private health insurance supplementing public health insurance. By giving details on the legislation and on the tax benefits associated with each type of contract (compulsory group contract, voluntary group contract and individual contract), we explain how the former nature of contract may be considered as a proxy for the price increase. The subsequent section provides a description of the data set and the model used. Our results and estimations are presented in the penultimate section that is followed by a discussion in the final section.

\section{The former nature of a contract: a proxy of the potential price increase}

In France, health insurance is divided into two parts: public insurance and supplementary private health insurance. Public health insurance is compulsory and universal $^{13}$ and funds about 77 per cent of health care expenditure, a share that has been quite stable over the past 10 years. Its contribution is particularly high for hospital care (92 per cent), lower for ambulatory care (66 per cent) and poor for some specific types of care such as eyewear and dental prostheses. ${ }^{14}$ Supplementary private health insurance covers the payment of the share not covered by public health insurance. The share of total expenditure funded by private supplementary insurance might appear rather modest (around 13 per cent of total health care expenditure) even if supplemental private health insurance is now recognised as playing a fundamental role in access to health care. The share of health care expenditure that may be automatically funded by private health insurance is high when the share of copayments not covered by public insurance is highest (dental care, eyewear, and extrafees for consultations with certain specialists). This is the reason why nearly 90 per cent of French people benefit from a private supplementary insurance scheme (despite

\footnotetext{
${ }^{12}$ As explained later on, in the context of group contracts, a significant share of the premium is paid directly by the employer. Buchmueller (2000) showed that this subsidy is usually considered as a part of the wage, but it clearly changes the burden of the insurance premium from the viewpoint of the person insured, see Currie and Madrian (1999) for a survey of the studies on the link between wages and employers' provision of a health insurance contract.

${ }^{13}$ In 2000, the Universal Health Insurance Act changed the basis for entitlement to public insurance from professional activity to proof of residence, thereby allowing all individuals to benefit from the same rights.

${ }^{14}$ Couffinhal and Perronnin (2004).
} 
marked heterogeneity across private contracts in terms of the warranties provided) and why public authorities implemented a voucher system to favour access to private insurance for the poor ${ }^{15}$ since 2004 .

The market for private insurance in which individuals and employers purchase contracts is highly competitive. The French private health insurance market is weakly concentrated. The top 10 operators account for hardly 25 per cent of total turnover, whereas in the German social health insurance market, for example, this share exceeds 50 per cent. ${ }^{16}$ Three types of insurers are active in the French market: (1) mutuelles (mutual benefit societies), these are the historical providers of such insurance and are non-profit organisations mainly offering individual contracts $(75$ per cent of their turnover) with still limited use of risk-rating or risk-selection strategies; (2) provident institutions (PI), which are non-profit organisations mostly specialised in compulsory group contracts (80 per cent of their turnover); (3) finally, there are the commercial health insurance companies which are for-profit organisations that share their health insurance activities between individual and group markets (60 per cent of their turnover comes from individual contracts and 40 per cent from group contracts) and practice relatively strong adjustments for individual risk in individual contracts. The three types of operators differ in many respects: their organisational objectives, the share health represents in their respective overall portfolios, the way they are regulated, etc. ${ }^{17}$ Supplementary health insurance contracts can be purchased either by individuals themselves or by their employers, the latter adding them as a benefit to the employee's salary package (in 2003, 40 per cent of French firms employing 72 per cent of employees offered group contracts according to a Protection Sociale Complementaire d'Entreprise survey). Nearly two policyholders in three obtain their coverage through their employer. Usually and whatever the type of insurer, group contracts offer several advantages compared to individual contracts. On average, the warranties offered are much more generous than those available through individual contracts. ${ }^{18}$ This can be explained by a lower degree or even a lack, in the case of compulsory contracts, of adverse selection in these contracts. Moreover, for a given set of warranties, premiums are lower than those achievable in the context of individual contracts. This is due simultaneously to the employer's contribution, which finances on average half of the premium, ${ }^{19}$ lower loading fees due to economies of scale associated with purchasing insurance through a group ${ }^{20}$ and finally, to tax exemptions for employees' contributions to the residual premium for compulsory contracts. Moreover, community-rated premiums (systematically for compulsory contracts and almost systematically for optional contracts) offer an additional price benefit to employees, though mainly for older ones.

\footnotetext{
${ }^{15}$ Not poor enough to benefit from the supplementary health insurance coverage provided for by the CMU Act.

${ }^{16}$ Schut et al. (2003).

${ }^{17}$ See Buchmueller and Couffinhal (2004).

${ }^{18}$ Couffinhal and Perronnin (2004).

${ }^{19}$ Couffinhal et al. (2004).

${ }^{20}$ Buchmueller (2000).
} 
Considering the financial advantages offered to workers enrolled in a health insurance group contract, it seems coherent to assume that the switching of private supplementary coverage may differ from one type of policyholder to another. Thus, the switching behaviour of new retirees should be explained by the nature of the former contract. In the French context, the difference of magnitude of premiums increases at retirement between group and individual contracts, offering the opportunity to study the marginal price effect on switching behaviours. Indeed, the nature of contract (compulsory group contract, voluntary group contract and individual contract) may be considered as an indirect measurement of the price effect. In this analysis, we therefore focus on the role of the nature of the former contract (prior to retirement) and check for a large number of individual characteristics that may influence health insurance demand. Moreover, we pay particular attention to the effect of the type of private insurer managing the contract owned prior to retirement.

At retirement, former group contract beneficiaries lose all the financial advantages mentioned above. The Evin Law of 31 December 1989, which was the first major public intervention in the private health insurance market, aimed primarily at limiting "risk selection" and increasing the portability of warranties. For compulsory group contracts, the law requires insurers to offer the new retiree a contract providing similar warranties to the group contract as well as cap the increase in premiums. In fact, by adding different premium increases due to the loss of group pricing (capped at 50 per cent), and to the loss of the employer's contribution, the premium actually paid by the new retiree can increase by almost 200 per cent. Sharper increases may be observed in the context of voluntary group contracts for which increases in premiums are not regulated by law.

\section{Data and methods}

\section{Data source and sample construction}

This study is based on the Health, Health Care and Insurance Survey (ESPS) carried out between 1994 and 2004 on French individuals covered by the public health insurance system. ${ }^{21}$ For each policyholder, in addition to data on the insurance contract, the panel ${ }^{22}$ includes standard socio-economic characteristics and individual indicators of health status. This survey, performed on around 20,000 individuals, was carried out every year between 1994 and 1997 and became bi-annual afterwards. Between 1994 and 2004, we identified three observation dates per policyholder $(T 1$, T2, T3): the individuals interviewed in 1994 and in 1995 were gathered together to constitute the first observation date (T1). They were re-interviewed in 1998 (constituting T2) and finally in 2002 (constituting T3). The individuals interviewed in 1996 and in 1997 were gathered together to constitute the first observation date of these individuals (T1). They were re-interviewed in $2000(T 2)$ and finally in 2004 (T3)

\footnotetext{
${ }^{21}$ Three different non-competing health insurance funds catering for the different segments of the labour market constitute the public health insurance system: CNAMTS, for salaried workers, MSA, for agricultural workers and RSI, for self-employed workers.

${ }^{22}$ The survey covers data from the same households collected every 4 years on average.
} 
Date $T 1$
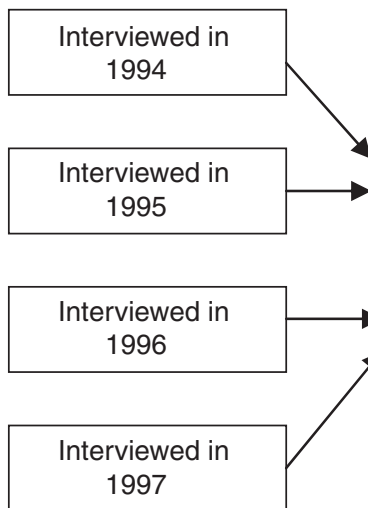

Date T2

Date T3

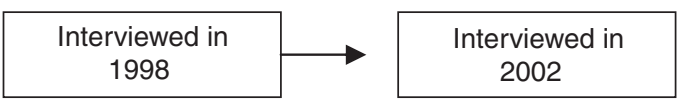

Interviewed in 2004

Figure 1. Three observation dates per policyholder between 1994 and 2004.

(see Figure 1). In order to pick up new retirees we had to select individuals whose status had changed from "in-work" to "retired" between two observation dates. This enabled us to compare their complementary health coverage provider just before and just after retirement (with a 4-year interval or, less frequently, an 8-year interval). Only subscribers of a private supplementary health insurance contract have been retained as we assumed that switching from one private operator to another is the result of their own decision. This excludes de facto the beneficiaries of Couverture Maladie Universelle Complémentaire ${ }^{23}$ (CMU-C) mainly administrated by local public funds. Furthermore, because of recoding problems, we excluded individuals who subscribed to several insurance contracts.

Finally, the sample provides information on 910 subscribers whose average retirement age is 59 (see Table 1). The database provides a wide variety of information for each subscriber, which can be classified in two groups. On the one hand, the database provides standard individual characteristics such as age, sex, education and date dependant variables such as occupation, ${ }^{24}$ income ${ }^{25}$ and health status. Health is measured by several indicators: the vital risk corresponding to a higher probability of death established on the basis of individuals' response to a statement on a six-point Likert scale, that is, from "no essential risk" to "a definite poor prognosis" and defined as an 80 per cent probability of death within 5 years; disability based on potential chronic illnesses resulting in a permanent handicap determined by an

${ }^{23}$ CMU-C is a free plan that provides full coverage of public health insurance co-payments, without any out-of-pocket payments. Targeting the poorest households, it is available as a function of financial resources (income below $€ 606$ per month for a single person) and covers 7.5 per cent of the population.

${ }^{24}$ The retirement date corresponds to the last wave in the survey in which the individuals in our sample were in employment.

${ }^{25}$ Taking into account household income adjusted for inflation, we built a variable to understand the change in income experienced during the transition to retirement: "same income", "higher income after" and "lower income after." 
Table 1 Description of the 910 retirees

\begin{tabular}{|c|c|c|}
\hline & Number & Percentage \\
\hline Total & 910 & 100.0 \\
\hline \multicolumn{3}{|l|}{ Switching behaviour } \\
\hline Switch from one insurer to another & 303 & 33.3 \\
\hline No switch from one insurer to another & 607 & 66.7 \\
\hline \multicolumn{3}{|l|}{ Gender } \\
\hline Male & 531 & 58.4 \\
\hline Female & 379 & 41.6 \\
\hline \multicolumn{3}{|l|}{ Type of former contract } \\
\hline Compulsory membership group contract & 201 & 22.1 \\
\hline Voluntary membership group contract & 226 & 24.8 \\
\hline Individual contract & 448 & 49.2 \\
\hline Unknown & 35 & 3.9 \\
\hline \multicolumn{3}{|l|}{ Type of insurer } \\
\hline Commercial company & 177 & 19.5 \\
\hline Mutual benefit society & 609 & 66.9 \\
\hline Provident institution & 124 & 13.6 \\
\hline \multicolumn{3}{|l|}{ Opinion about benefits } \\
\hline Bad & 46 & 5.1 \\
\hline Fair & 123 & 13.5 \\
\hline Good, Excellent & 520 & 57.1 \\
\hline Unknown & 221 & 24.3 \\
\hline \multicolumn{3}{|l|}{ Public fund } \\
\hline Main public fund CNAMTS & 496 & 54.5 \\
\hline Other public funds MSA/RSI & 414 & 45.5 \\
\hline \multicolumn{3}{|l|}{ Co-payments } \\
\hline Regular co-payments & 821 & 90.2 \\
\hline Co-payments exempted & 89 & 9.8 \\
\hline \multicolumn{3}{|l|}{ Age at retirement } \\
\hline Before 59 yrs & 492 & 54.1 \\
\hline After 59 yrs & 418 & 45.9 \\
\hline \multicolumn{3}{|l|}{ Education } \\
\hline High school or lower & 691 & 75.9 \\
\hline Higher education & 175 & 19.2 \\
\hline Unknown & 44 & 4.9 \\
\hline \multicolumn{3}{|l|}{ Vital risk } \\
\hline None & 239 & 26.3 \\
\hline Moderate & 444 & 48.8 \\
\hline High & 111 & 12.2 \\
\hline Unknown & 116 & 12.7 \\
\hline \multicolumn{3}{|l|}{ Income variation } \\
\hline Increase & 146 & 16.0 \\
\hline
\end{tabular}


Table 1 Continued

\begin{tabular}{lrr}
\hline & Number & Percentage \\
\hline No change & 314 & 34.5 \\
Decrease & 61 & 6.7 \\
Unknown & 389 & 42.8 \\
& & \\
Period of retirement & 332 & 36.5 \\
Between dates T1 and T2 & 362 & 39.8 \\
Between dates T2 and T3 & 216 & 23.7 \\
Between dates T1 and T3 & & \\
\hline
\end{tabular}

answer on an eight-point Likert scale, that is, from "no impairment" to "permanently bed-ridden"; and, last but not least, perceived health status based on an individual score from "very poor health" (0) to "excellent health" (10). On the other hand, the database gives information on private insurance contracts such as the nature of contract before and after retirement (compulsory, voluntary group or individual contract $^{26}$ ), the type of private operator (mutual benefit society, provident institution or insurance company) and the individual assessment of the warranties provided by the insurer particularly for specialist care: "poor opinion" of payments, "fair opinion" or "good opinion."

We analyse the role of all these factors in the decision to switch from one insurer to another.

The data allows us to observe the switching decision as long as the individual opts for a different provider; however, we do not identify the change of contract within the same provider. For the sake of simplicity, we talk about the switching (or not) of supplementary health provider at the moment of retirement, knowing that we underestimate the overall switching rate.

\section{Exploratory analysis}

In the database, almost 22 per cent of individuals benefit from a compulsory group contract, 25 per cent from a voluntary group contract and 49 per cent from an individual contract. Table 2 provides summary statistics about switching rates according to the nature of the former contract: 51 per cent of individuals affiliated with a compulsory group contract switch at retirement, while the figures are 39 per cent and 23 per cent, respectively for beneficiaries of a voluntary group contract and those of individual contracts. These switching rates suggest that the assumption of a significant impact of the nature of the former contract is relevant. Nevertheless, all the other variables and particularly certain other characteristics of contracts may influence the switching decision. For instance, the fact that the three types of providers supply different forms of contracts whether they target individual or collective demand may

\footnotetext{
${ }^{26}$ We rank health insurance contracts of state employees among individual contracts due to their nonbinding nature and the employer's non-participation in financing the premium.
} 
Table 2 Switching rate according to nature of contract

\begin{tabular}{lcc}
\hline Nature of former contract & Subscribers $n=910$ & Switching rate $(\%)$ \\
\hline Compulsory group & 201 & 51 \\
Optional group & 226 & 39 \\
Individual & 448 & 23 \\
Unknown & 35 & 3 \\
\hline
\end{tabular}

Table 3 Switching rate relating to type of provider

\begin{tabular}{lrc}
\hline & $N$ & Switching rate $(\%)$ \\
\hline Insurance companies & 97 & 54,80 \\
Provident institutions & 53 & 42,74 \\
Mutual societies & 153 & 25,12 \\
\hline
\end{tabular}

Table 4 Type of provider chosen by policyholders who decided to switch

\begin{tabular}{lccccc}
\hline Type of provider before retirement & \multicolumn{4}{c}{ Type of provider after retirement } \\
\cline { 2 - 6 } & $\begin{array}{c}\text { No cover } \\
(\%)\end{array}$ & $\begin{array}{c}\text { Insurance } \\
\text { companies (\%) }\end{array}$ & $\begin{array}{c}\text { Provident } \\
\text { institutions (\%) }\end{array}$ & $\begin{array}{c}\text { Mutual } \\
\text { societies }(\%)\end{array}$ & $\begin{array}{c}\text { Total } \\
(\%)\end{array}$ \\
\hline Insurance companies & $2^{\mathrm{a}}$ & 41 & 24 & 33 & 100 \\
Provident institutions & $9^{\mathrm{a}}$ & $11^{\mathrm{a}}$ & 38 & 42 & 100 \\
Mutual societies & $6^{\mathrm{a}}$ & $9^{\mathrm{a}}$ & $9^{\mathrm{a}}$ & 76 & 100 \\
\hline
\end{tabular}

${ }^{\mathrm{a}}$ Low strength: percentages that have to be treated with caution $(<20$ persons).

bias immediate interpretations of descriptive statistics. Mutual benefit societies and commercial insurance companies mainly intervene on individual contract supply (respectively 75 per cent and 60 per cent of their turnover), whereas provident institutions (PI) concentrate on group contracts ( 80 per cent of their turnover). Table 3 provides a more detailed description of switching behaviours regarding the type of former provider. Switching behaviours are more frequent among those formerly insured by an insurance company ( 55 per cent) vs. those formerly covered by a provident institution (43 per cent) and finally vs. individuals formerly covered by a mutual benefit society ( 25 per cent). Table 4 shows the type of provider selected among policyholders who decided to switch regarding their respective former types of provider. Indeed, each of them may decide whether to change their type of provider or remain affiliated with a provider of the same type. Among policyholders who decided to switch, only 41 per cent of those formerly insured by an insurance company, that is, those who switch most, selected another insurance company while a third of them opted for a mutual benefit society. Among the 43 per cent of those formerly covered by a PI who decided to switch, only 38 per cent of them decided to select another PI. The 
620

policyholders who switch least are those formerly affiliated to a mutual benefit society (only a quarter of them) and 76 per cent of them select another mutual benefit society.

In order to analyse efficiently the price effect whose proxy is the nature of the contract, we had to isolate the relative effect of all these variables by running a model considering that "all other factors are equal."

\section{Method}

A probit model was used to estimate the probability of switching providers. Taking into account that the nature of a former contract could generate quite large ranges of increase in premiums at retirement, we had to estimate switching behaviour by controlling effects that are not directly linked to the nature of contract. Thus, we considered the binary variable $Y i$ defined by $Y i=1$ if the individual switched and $Y i=0$ otherwise.

$$
P(Y i=1 / Z i, X i, \Delta R i)=a+\beta Z i+\gamma X i+\delta \Delta R i+\varepsilon
$$

where $Z i$ represents the nature of the former contract (compulsory, voluntary or individual); $X i$ and $\Delta R i$ represent control variables: $X i$ is a vector of individual characteristics before retirement (education, age of retirement, retirement wave, type of provider, individual assessment of payments for specialist care, public fund, public co-payment exemption and vital risk) and $\Delta R i$ represents the difference in income before and after retirement: "same income," "higher income after" and "lower income after." Standard error $\varepsilon$ is assumed to follow a cumulative normal distribution.

This model allows for calculating marginal effects. We estimated the individual probability to switch through the estimation of parameters $(\alpha, \beta, \gamma$ and $\delta)$, then computed these estimated probabilities to calculate the mean probabilities for the different groups defined by our variables, every thing else being equal. The magnitudes of the differences in mean probabilities were analysed in order to understand the differences in switching behaviour.

\section{Results}

Table 5 presents the results of the probit regression. All factors being equal, the switching probability is significantly higher for individuals enrolled in a group contract before retirement than for those who hold an individual contract, that is, it is 13 per cent higher for retirees formerly covered by a voluntary group contract and 21 per cent higher for those previously covered by a compulsory contract. The higher switching rate observed for group contract holders can be explained by the various financial benefits available for employees enrolled in a group contract. Indeed, retirement may lead to potentially higher increases in premiums due to the loss of pooled pricing on the one hand and to the loss of the employer's subsidy on the other, both generating a sharp rise in premiums. The difference in estimated switching behaviour between policyholders formerly enrolled in a group contract and those formerly insured by an individual contract is in line with our price effect assumption: it emphasises the expected rational behaviour of the individuals facing a high increase in prices. 
Table 5 Marginal probability of switching behaviour

\begin{tabular}{|c|c|c|}
\hline & Variation of probability percentage points & Significance \\
\hline \multicolumn{3}{|c|}{ Supplementary health insurance characteristics } \\
\hline Type of contract: individual contract & ref. & ref. \\
\hline Compulsory group contract & 21 & $* * *$ \\
\hline Voluntary group contract & 13 & $* * *$ \\
\hline Unknown & 12 & \\
\hline Provider: mutual benefit society & $r e f$. & ref. \\
\hline Commercial company & 26 & $* * *$ \\
\hline Provident institution & 6 & \\
\hline Opinion about benefits: Bad & ref. & ref. \\
\hline Fair & -3 & \\
\hline Good, excellent & 3 & \\
\hline Unknown & 2 & \\
\hline \multicolumn{3}{|l|}{ Public health insurance characteristics } \\
\hline Main public fund CNAMTS & ref. & ref. \\
\hline Other public funds $M S A, R S I$ & -13 & $* * *$ \\
\hline Regular co-payments & ref. & ref. \\
\hline Co-payments exempted & 1 & \\
\hline \multicolumn{3}{|l|}{ Individual characteristics } \\
\hline Age at retirement: before $59 \mathrm{yrs}$ & ref. & ref. \\
\hline After 59 yrs & 3 & \\
\hline High school or lower & ref. & ref. \\
\hline Higher education & -10 & $* *$ \\
\hline Unknown & 6 & \\
\hline Vital risk: none & ref. & ref. \\
\hline Moderate & -5 & \\
\hline High & -10 & $*$ \\
\hline Unknown & -8 & \\
\hline Income variation: increase & 4 & \\
\hline No change & $r e f$. & ref. \\
\hline Decrease & 3 & \\
\hline Unknown & -3 & \\
\hline \multicolumn{3}{|l|}{ Period of retirement } \\
\hline Between dates 1 and 2 & ref. & ref. \\
\hline Between dates 2 and 3 & -3 & \\
\hline Between dates 1 and 3 & 12 & $* * *$ \\
\hline
\end{tabular}

The results of the model $(\alpha, \beta, \gamma$ and $\delta)$ are available on request.

The probability of a policyholder holder characterised by all references to switch at retirement is 31 per cent. The effect of each characteristic on the dependent variable is given in percentage points with regard to the reference (ref.). $\left.\left[{ }^{* * *}\right],{ }^{* *}\right]$ and $\left[{ }^{*}\right]$ indicate that the effect is significant at the 1 per cent level, 5 per cent level and 10 per cent level.

Among policyholders formerly enrolled in a group contract, the probability to switch is higher for those whose membership was compulsory than for those for whom subscription was voluntary $(+21$ pts vs. +13 pts). Due to the reality of the group contracts market, this result does not have to be explained in terms of differences in 
premiums variation. Indeed, although it is not obligatory for employers to finance a share of the premium in the case of voluntary group contracts, they do so in practice and it appears that average levels of participation are similar for all group contracts (respectively 49 per cent for voluntary membership and 52 per cent for compulsory membership). ${ }^{27}$ Moreover, whereas providers have to apply group pricing in the case of voluntary group contracts, it appears that almost all of them apply this pricing model (only 4 per cent adjust the price to individual risk). ${ }^{28}$ Thus, the lower estimated probability to switch in the case of voluntary group contracts can be explained in another way: the decision to subscribe or not is in itself a rational choice of the optimal coverage already based on cost and personal needs (utility), whereas in the case of a compulsory group contract, everything is already established and there is no room for choice. Therefore, even though the average level of warranties in the case of compulsory contracts is relatively high, the warranties included in the package are not necessarily tailored to the needs of retirees. ${ }^{29}$

Everything else being equal, policyholders covered by a commercial insurance company before retirement changed their insurer more frequently than those previously covered by a mutual benefit society $(+26 \mathrm{pts})$. It should be recalled that among policyholders who decided to switch their provider at retirement, more than half formerly insured through a commercial insurance company also change their type of provider (mutual benefit society or PI). This higher probability is the result of two different switching behaviours: first, changes related to an anticipation of an increase in premiums (over time) due to a significant pricing risk often used by the insurance company may explain the choice of a mutual benefit society or a PI. Second, greater competition among insurance companies offering broader ranges of warranties ${ }^{30}$ may also explain a higher switching rate within this type of operator.

It appears that the vital risk prior to retirement is the sole indicator of health status that has a significant impact on switching behaviour: subscribers in very poor health (high vital risk) have a lower probability ( -10 per cent) to switch from one provider to another one compared to rather healthy individuals (no vital risk). This result could suggest that individuals in poor health face certain barriers to switching, perhaps because of selection implemented by providers. However, although these results are interesting, they are not very robust. In fact, our model does not highlight significant effects of health status with the other indicators tested, namely "disability" and "perceived health status." Likewise, we tested the assumption that change in health status (being in better or in worse health after retirement) impacts switching behaviour. Unlike the results obtained by Grignon and Sitta, ${ }^{31}$ our model failed to highlight a significant role of change in health status on the retirees' switching behaviour.

\footnotetext{
${ }^{27}$ Enquête Protection Sociale d'Entreprise (2003): the authors' computations.

${ }^{28}$ Couffinhal et al. (2004).

${ }^{29}$ Due to the lack of statistical power of our model, note that the difference in the probability of switching between policyholders enrolled in compulsory and voluntary group contracts is not statistically significant.

${ }^{30}$ Martin-Houssart et al. (2005).

${ }^{31}$ Grignon and Sitta (2003).
} 
Moreover, note that individuals who do not have public co-payments, mainly due to long-term disease (ALD), do not adopt a specific switching behaviour, despite the fact that this classification (ALD) reflects rather deteriorated health. This result could suggest that public insurance coverage can significantly reduce the additional risk characterising these individuals, placing them in a comparable situation in the private insurance market to other retirees, despite the "poor" health observed.

Individuals insured before retirement by the one of the two other public funds, RSI (Régime social des indépendants) or MSA (Mutualité sociale agricole), have a much lower probability $(-13$ pts) to switch than individuals affiliated with the main public funds (Caisse Nationale d'Assurance Maladie des Travailleurs Salari, CNAMTS). In our sample, most of the individuals not covered by CNAMTS are beneficiaries of the RSI. Until 2002, the majority of those insured by RSI had to bear lower public compensations than any other policyholders. Consequently, their lower switching behaviour suggests that they are used to relying more on their private insurance to gain access to the health care system than policyholders covered by the main public funds (CNAMTS).

We also noted that, all other factors being equal, retirees who had experienced a reduction in their resources do not change provider more frequently. This result suggests that income may not play a significant role. This unexpected result is probably the consequence of the approximate and irregular method for monitoring income through time, leading to the creation of increasingly broad income bands. This problem of collecting income data is compounded by that of no available data.

We observed that the most highly educated policyholders have a lower probability of changing provider. This result, which contradicts the intuition that the most educated individuals have easier access to information, is however in line with previous results obtained in general population studies (Grignon and Sitta, 2003). ${ }^{32}$ One can assume that the level of education (high school and lower/higher education) reached 40 years ago is not a good proxy for the ability of a new retiree to read and understand a contract for health insurance. Indeed, experience gained over time reduces the effect of initial education.

\section{Discussion}

The results of our study show that switching behaviours from one private health insurer to another are relatively frequent during the transition to retirement, since an average of one retiree in three decides to switch. Compared with the estimated switching rates on samples of the general population, it appears that change in status in the labour market is a major cause of mobility in the market for private health insurance. Far from contradicting earlier works, our results confirm the findings of

\footnotetext{
${ }^{32}$ Ibid.
} 
Grignon and Sitta. ${ }^{33}$ Retirement is a key period when the effects of both income and prices through insurance premiums accumulate.

Our results confirm that there is a price effect as policyholders formerly enrolled in a group contract switch much more frequently than those formerly benefiting from an individual contract. We also show that switching behaviours cannot be explained only in terms of the addition of different price effects: for comparable levels of premium increases, policyholders enrolled in compulsory group contracts change more frequently than those enrolled in voluntary group contracts, probably to take advantage of the transition to retirement to build up a set of insurance warranties that suits them better.

However, our study is limited in some respects. The main limitation is a consequence of our data: we underestimate mobility on the private health insurance market as we only consider inter-company mobility. Indeed, we have no data on intracompany mobility, meaning that we only know when a policyholder switches from one private insurer to another, but not when this policyholder changes from one contract to another with the same private insurer. Another limitation concerns our method. Indeed, the model used allows us to isolate the effect of the nature of contract (that we consider as being a proxy of the price effect) from the other factors introduced in the model. The price effect could be biased if the nature of the initial contract is linked to unobservable variables that may influence the decision to change provider. More precisely, our model is based on the assumption that all policyholders have the same degree of risk aversion. If we decided not to keep this hypothesis, then people with higher risk aversion and who are assumed to be the least mobile on the supplementary private health insurance market, could not initially be distributed randomly between the different contracts (group or individual). We could, for example, consider that policyholders who previously benefited from a compulsory group contract are more likely to be averse to risk. This distortion exists and is not controlled by the model. However, this distortion illustrating that the choice to work for a specific organisation could depend on whether or not it offers a group insurance contract is not very significant in the French context (it is less significant than in the American market, for instance). Indeed in France, private insurance coverage supplements a rather large but non-uniform share of public insurance coverage. Moreover, another explanation for this distortion may be the fact that independent workers, usually assumed to be less averse to risk than people on a payroll, are underrepresented among group contract beneficiaries. This does not distort our results as we control the characteristic of being an independent worker indirectly via their public health insurance, namely RSI.

Our results clearly show that mobility is high during this particular period of retirement characterised by a change in both socioeconomic status and in risk status due to age. However, private health insurance in France only covers a segment of the policyholder's health care, that is, primary care, eye and dental care, whereas hospital care is almost entirely covered by public health insurance. The question is whether the respective shares of private and public health insurance are likely to increase mobility 
during the transition to retirement. Due to the lower overall risk covered by private insurance, individuals might be expected to be more sensitive to price changes corresponding to a more elastic insurance demand, which should be reflected in higher switching rates. On the contrary, if we consider private health insurance as a superior good, and since public health insurance covers the most expensive part of the risk, then those individuals who feel "richer" should raise their share of private health insurance expenditure. It could be interesting to focus on this question due to the changes affecting the respective shares of private and public health insurance.

Moreover, in order to understand more precisely the determinants of the health insurance demand of new retirees, it could be very useful to obtain information on the content of the different contracts in order to run a qualitative analysis of insurance demand. The heterogeneity of supplementary health insurance contracts (in terms of the warranties included) should increase due to the gradual expansion of the scope of private insurance. Thus, purchasing a supplementary insurance contract does not guarantee full access to health care and such analysis could become increasingly relevant.

New retirees are one of the most mobile population groups in the supplementary health insurance market. Considering the high level of saturation of this market, this group can be an attractive target for insurers. The downside is that new retirees are likely to be in a fragile position due to more difficult access to private health insurance and therefore to the health care system in general.

\section{References}

Beaulieu, N. (2002) 'Quality information and consumer health plan choices', Journal of Health Economics 21(2): 43-54.

Buchmueller, T.C. (2000) The Business Case for Employer-Provided Health Benefits: A Review of the Relevant Literature, Oakland, CA: California HealthCare Foundation.

Buchmueller, T.C. and Couffinhal, A. (2004) Private health insurance in France, OECD Health Working Paper 12, Paris.

Couffinhal, A., Grandfils, N., Grignon, M. and Rochereau, T. (2004) Enquête sur la protection sociale complémentaire d'entreprise en France, Rapport IRDES 1540, Paris.

Couffinhal, A. and Perronnin, M. (2004) 'Accès à la couverture complémentaire maladie en France: Une comparaison des niveaux de remboursement - Enquêtes ESPS 2000 et 2002', Questions d'économie de la sant 80: $1-6$.

Currie, J. and Madrian, B.C. (1999) 'Health, health insurance and the labour market', Handbook of Labor Economics 3: 3309-3415.

Frank, R. and Lamiraud, K. (2008) 'Choice, price competition and complexity in markets for health insurance', NBER Working Paper No. 13817.

Grignon, M. and Sitta, R. (2003) 'Qui change de complémentaire santé et pourquoi? Une étude longitudinale à partir de l'enquête ESPS 1988-98', Questions d'économie de la sant 64: 1-6.

Gruber, J. (2000) 'Health insurance and the labor market', Handbook of Health Economics 1: 645-706.

Laske-Aldershof, T., Schut, E., Beck, K., Greß, S., Shmueli, A. and Van de Voorde, C. (2004) 'Consumer mobility in health insurance markets: A five-country comparison', Applied Health Economics and Health Policy 3: 229-241.

Martin-Houssart, G., Rattier, M.O. and Raynaud, D. (2005) 'Les contrats offerts en 2002 par les organismes d'assurance maladie complémentaire', Etudes et résultats - DREES 402: 1-12.

Rogowski, J. and Karoly, L. (2000) 'Health insurance and retirement behaviour: Evidence from the health and retirement survey', Journal of Health Economics 19: 529-539. 
Saliba, B. and Ventelou, B. (2007) 'Complementary health insurance in France: Who pays? Why? Who will suffer from public disengagement?', Health Policy 81: 166-182.

Samuelson, A. and Zeckhauser, R. (1988) 'Status quo bias in decision making', Journal of Risk and Uncertainty 1: 7-59.

Schut, F.T., Greß, S. and Wasem, J. (2003) 'Consumer price sensitivity and social health insurer choice in Germany and the Netherlands', International Journal of Health Care Finance and Economics 3: 117-138.

\section{About the Authors}

Carine Franc is an economist and a permanent researcher at the French national public research body entirely dedicated to human health, Institut National de la Santé et de la Recherche Médicale. She received a $\mathrm{PhD}$ in Economics from Toulouse School of Economics, Toulouse University, France, in 2000.

Marc Perronnin is a senior research fellow at the IRDES, the Institute for Research and Information in Health Economics.

Aurélie Pierre is a research fellow at the IRDES, the Institute for Research and Information in Health Economics. 